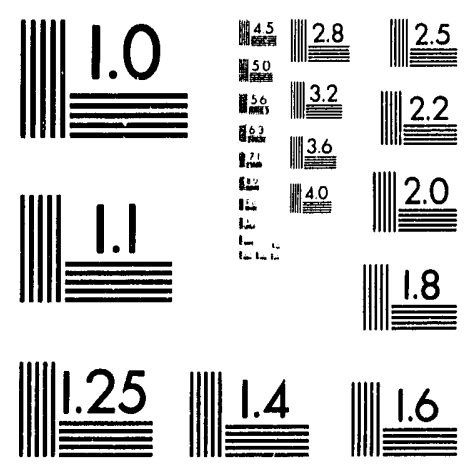



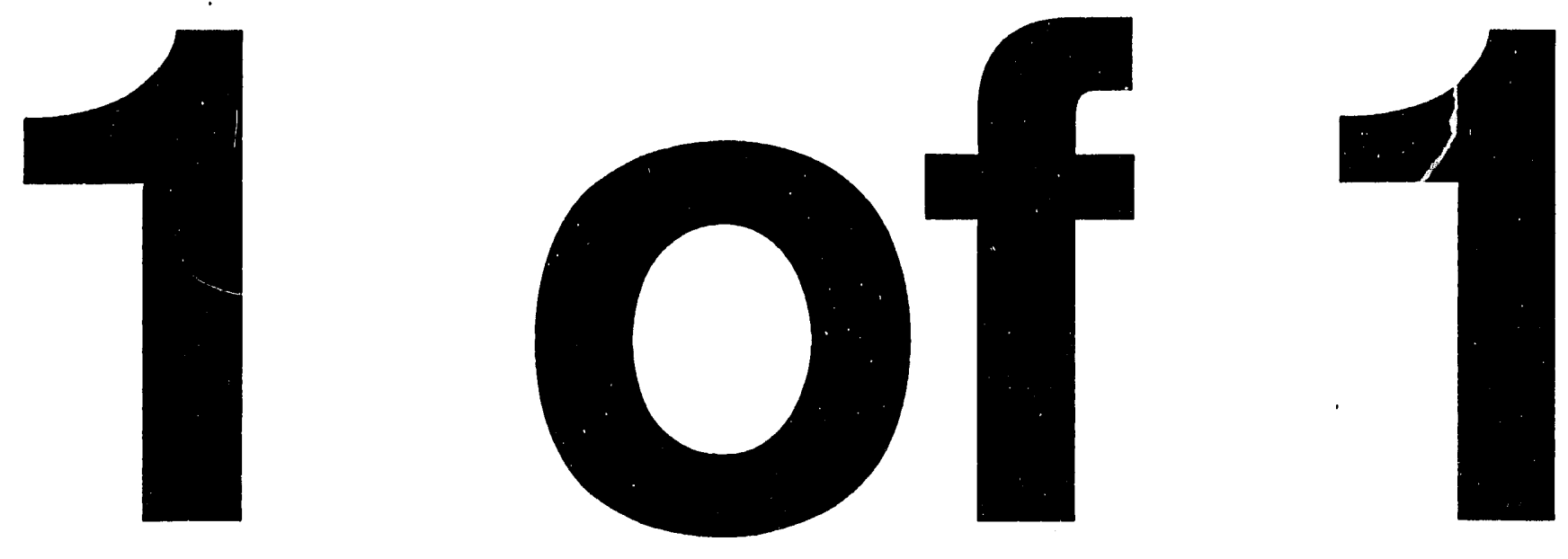


\title{
COMPATIBILITY OF ALTERNATIVE REFRIGERANTS WITH VARNISHED MAGNET WIRE
}

\author{
Robert Doerr and Stephen Kujak \\ The Trane Company \\ La Crosse, WI
}

\begin{abstract}
The compatibility of 24 motor materials with 11 pure refrigerants and 17 refrigerant-lubricant combinations was determined under a $\$ 382,000$ contract funded by the Department of Energy (DOE) and administered by the Air-Conditioning and Refrigeration Technology Institute (ARTI). This article is a summary of the effect of refrigerants on varnished magnet wire.
\end{abstract}

The greatest effect on the motor materials was caused by absorption followed by desorption of refrigerants at higher temperatures. The high internal pressure of the absorbed refrigerants and the tendency of these refrigerants to evolve from the materials resulted in blisters, cracks and internal bubbles in the varnish and magnet wire insulation. The degradation of the insulation resulted in changes in the bond, dielectric and burnout strength of the varnished magnet wire. Desorption of HCFC-22, and to a lesser extent HFC-32. HFC-134 and HFC152a, had the greatest effect on insulation integrity.

Of the refrigerants tested, exposure to HCFC22 produced the most deleterious effects on the magnet wire insulation and varnishes. Since many of the materials tested have excellent reliability with HCFC-22 in current applications, these materials are expected to be reliable when used with the new refrigerants.

\section{INTRODUCTION}

Because of ozone depletion attributed to the chlorofluorocarbons(CFC's), a program to develop alternative refrigerants is currently underway. An environmentally acceptable refrigerant includes hydrogen (HCFC) to decrease atmospheric life and/or excludes chlorine (HFC) to eliminate ozone depletion. A primary requirement of a new refrigerant is compatibility with the hermetic motor materials.
The compatibility of polymeric insulation material with refrigerants depends on two primary modes of interaction: absorption of refrigerant and extraction by refrigerant.

Absorption of the refrigerant can affect the insulation material by changing its dielectric strength or physical integrity. Absorption can cause excessive swelling, softening or decreased strength. In addition to the direct effect of the absorbed refrigerant, a more deleterious effect may occur due to rapid desorption of the refrigerant. Absorption and desorption can result in high internal pressures causing blisters, crazing, surface craters or bubbles within the insulating material. A pronounced decrease in the dielectric and physical strength of the material is often observed.

Extraction of material by the refrigerant results in a range of effects varying from complete dissolution to only a slight change in properties as a result of dissolving only unpolymerized material. The usual effect of the extraction on insulation materials is embrittlement caused by extraction of low molecular weight polymers(oligomers) or plasticizers. Extraction or chemical dissolution of a material can also cause serious problems within hermetic systems by causing components to stick or by clogging passages such as capillary tubes.

The data presented in this paper show the effects of absorption, desorption and extraction on the physical properties of the insulating materials. Results immediately after the 500 hour exposures illustrate the effects of absorbed refrigerant on insulation properties such as bond strength, burnout resistance, and dielectric strength. The results after the $150^{\circ} \mathrm{C}\left(302^{\circ} \mathrm{F}\right)$ bake in air, following the refrigerant or refrigerant-lubricant exposure, indicate the effects of desorption on the same properties. 


\section{DISCLAIMER}

This report was prepared as an account of work sponsored by an agency of the United States Government. Neither the United States Gnvernment nor any agency thereof, nor any of their employees, makes any warranty, express or implied, or assumes any legal liability or responsibility for the accuracy, completeness, or usefulness of any information, apparatus, product, or process disclosed, or represents that its use would not infringe privately owned rights. Reference herein to any specific commercial product, process, or service by trade name, trademark, manufacturer, or otherwise does not necessarily constitute or imply its endorsement, recommendation, or favoring by the United States Government or any agency thereof. The views and opinions of authors expressed herein do not necessarily state or reflect those of the United States Government or any agency thereof. 
Comparison of the compatibility data for refrigerant-lubricant combinations with that of pure refrigerants showed that, in general, pure refrigerants exhibited a greater effect on varnished magnet wire. This effect occured even though exposures to pure refrigerants were at a lower temperature.

The information presented in this report can best be interpreted by comparisons to a refrigerant with a history of reliability. Since pure HCFC-22 showed the most deleterious cffect on materials and has a weil documented reliability history, results were compared to HCFC-22.

\section{REFRIGERANTS AND MATERIALS EVALUATED}

This paper covers compatibility tests of three commercial magnet wires combined with six motor varnishes exposed to 11 pure refrigerants. Exposures were conducted in stainless steel pressure vessels. Magnet wire and varnish samples were covered with liquid refrigerant at an exposure temperature below critical temperature. Materials were evaluated in triplicate immediately after a 500 hour exposure and after a 500 hour exposure followed by an additional 24 hour bake at $150^{\circ} \mathrm{C}\left(302^{\circ} \mathrm{F}\right)$ in air to remove absorbed refrigerant. The effect of heat alone was determined by exposures in nitrogen gas.

The refrigerants, magnet wires, varnishes, and tests performed on the motor are listed below:

\section{REFRIGERANTS}

The motor materials were exposed to the 11 pure refrigerants for 500 hours at the temperatures indicated below. HFC-245ca, [1] a research chemical with properties similar to CFC-11 and HCFC-123, was added to the test program. The HCFC's included 22, 123, 124, and $142 \mathrm{~b}$. The HFC's included 32, 125, 134. 134a, 143a, 152a, and 245ca. Exposure temperature was $90^{\circ} \mathrm{C} / 194^{\circ} \mathrm{F}$ for all refrigerants except HFC-32, $-125,-143 a$ $\left(60^{\circ} \mathrm{C} / 140^{\circ} \mathrm{F}\right)$ and $\mathrm{HFC}-245 \mathrm{ca}$ $\left(121^{\circ} \mathrm{C} / 250^{\circ} \mathrm{F}\right)$.

\section{MAGNET WIRE AND VARNISHES}

\section{Magnet Wire}

-A. Modified polyester overcoated with polyamide imide per Section MW 73 of NEMA Standard MW 1000

- B. Modified polyester overcoated with polyamide imide and epoxy saturated glass per Section MW 73 and MW 46 of NEMA Standard MW 1000

- C. Polyester imide over coated with polyamide inide

\author{
Varnishes \\ -U475EH, solvent epoxy \\ -Y390PG, solvent epoxy-phenolic \\ -ER610, 93\% solids epoxy \\ -Y833, 100\% solids VPI epoxy \\ -923, solvent epoxy \\ -Isopoxy 800, water-borne epoxy
}

\section{EVALUATIONS PERFORMED}

Evaluations, in addition to visual examinations, were performed on the motor materials both before and after the exposures. Measurements, including bond, dielectric, and burnout strengths, were conducted according to standard methods[2].

\section{RESULTS}

The compatibility measurements after the 500 hour exposure to 11 pure refrigerants or 17 refrigeran-lubricant combinations are presented as 620 pages of data tables in Volumes II and III of the final report [3]. Pictures documenting observed changes comprise Volume IV. The 620 pages of data are summarized in 84 tables of average percent change from unexposed values. The percent change tables, procedures, motor material specifications, discussions, compatibility charts, etc., are located in Volume I of the report.

Percent change tables in this article will be restricted to the effect of pure refrigerants on the varnishes and Magnet wire A only. Discussion will include all three varnished magnet wires. 


\section{DISCUSSION}

\section{Varnishes}

Before discussing the effects of refrigerants on the bond, dielectric and burnout strengths of varnished magnet wires, it is best to examine the effects on pure varmish cast in the form of thın disks.

\begin{tabular}{|c|c|c|c|c|c|c|}
\hline & $\mathrm{Re}$ & $\begin{array}{r}\text { Var } \\
\% \text { Cha } \\
\text { alts afte }\end{array}$ & $\begin{array}{l}\text { ish Disks } \\
\text { ige in We } \\
500 \cdot 1100\end{array}$ & $\begin{array}{l}\text { hit } \\
\text { exposure }\end{array}$ & & \\
\hline & & & Varms! & Type & & \\
\hline Exposure to & 0.475 & $1-390$ & $\underline{E} \underline{R}-610$ & 1.833 & 110923 & 150.800 \\
\hline$N_{2}$ (a) 600 & $0.3 \%$ & $0.3 \%$ & 640 & $02 \%$ & $03 \%$ & $02 \%$ \\
\hline$N_{2}(a-g) C$ & $00 \%$ & $0.3 \%$ & 034 & $00 \%$ & $0.1 \%$ & $\rightarrow 3 \%$ \\
\hline$H C F, C 2$ & $16.9 \%$ & $12.5 \%$ & $18 \%$ & $134 x$ & $144 \%$ & $74 \%$ \\
\hline HCFC-123 & $27.6 \%$ & $246 \%$ & $255 \%$ & $4.40 \%$ & $262 \%$ & 13.94 \\
\hline HCFE 124 & $+8 \%$ & $24 \%$ & $\therefore+4 n$ & $\because 32^{23 \pi}$ & $18 \%$ & $09 \%$ \\
\hline $4 C F C+20$ & E $1 \%$ & $5.5 \%$ & 10.04 & $63 \%$ & $62 \%$ & $00 \%$ \\
\hline HFF: $52 a$ & $\begin{array}{ll}6 & 4 \% \\
1 & 7 \%\end{array}$ & $49 \%$ & $3 \%$ & $\begin{array}{l}81 \% \\
474 .\end{array}$ & $\begin{array}{l}5290 \\
159\end{array}$ & $01 \%$ \\
\hline$H F^{\circ}=34$ & $\because 5 \%$ & $4.5 \%$ & $9: 4$ & $76 \%$ & $73 \%$ & $110 \%$ \\
\hline HF $=125$ & $16 \%$ & $24 \%$ & 24 & $? 0 \%$ & $26 \%$ & $104 \pi$ \\
\hline HEE S $3 ?$ & $81 \%$ & $68 \%$ & $92 \mathrm{~m}$ & $95 \%$ & $51 \%$ & $+8^{\prime} *$ \\
\hline HFC.'山sa & $12 \%$ & $85 \%$ & $4 x^{2}$ & $21 \mathrm{th}$ & $17 \%$ & $1 \%$ \\
\hline HF $(\cdot 2 \cdot 2) 6 \mathrm{~d}$ & $<\%$ & .464 & 26, & $84 \pi$ & $32 \%$ & $23 \mu_{n}$ \\
\hline
\end{tabular}

I able I

HCFC-123 was absorbed to the greatest extent $(13.9 \%$ to $44.0 \%)$ by all varnishes followed by HCFC-22(7.4\% to $18.7 \%)$. Other refrigerants such as HCFC-124 (0.9-13.2\%) and HCFC-142b (0-10.0\%) were also absorbed in fairly large amounts by the varnishes. This trend suggested that HCFC's with some chlorine were generally absorbed to greater amounts than HFC's. However, HFC-32 (4.8-9.5\%), HFC$134(1.1-9.1 \%)$ and $\mathrm{HFC}-152 \mathrm{a}(0.1-9.1 \%)$ are absorbed to an extent similar to HCFC-124 and HCFC-142b, suggesting that other factors are involved besides the presence or absence of chlorine. For example, the refrigerants absorbed to the greatest extent and exhibiting the greatest effect on varnish disks and varnished magnet wire (HCFC-22, HFC-32, HFC-134 and HFC-152a) contained the -CHF 2 group.

The high absorption values for HCFC -123 lead to the expectation that HCFC-123 should cause the greatest compatibility concerns with varnishes. However. only the 833 varnish with $44 \%$ absorption, was found to be incompatible with HCFC -123 by this study and by previous studies [4]. Absorption of HCFC-123 as high as
?7.6\% by weight appeared to have little effect on the other varnishes.

Varmishes exposed to HCFC-22, and to a lesser extent HFC-32. HFC-134 and HFC-152a, exhibited internal bubbles and external blisters after the $150^{\circ} \mathrm{C}\left(302^{\circ} \mathrm{F}\right)$ bake, but HCFC- 123 and the other refrigerants did not exhibit this effect. This may be due to lower internal refrigerant pressure or to a slower rate of desorption for those refrigerants not affecting the varnishes.

\section{Magnet Wire}

The effects of refrigerants and refrigerantlubricants on the relatively thick varnish disks(0.05 inch) are only indications of potential problems that may occur with varnished magnet wires in actual motors. The varnish thickness on magnet wire in actual motors is only about 0.002 inch. As a further step to evaluate the effects, studies were conducted on actual varnished magnet wires. The three magnet wire types were tested unvarnished and varnished with six different varnishes.

\section{Bond Strength}

The greatest effect of the refrigerant absorption/desorption phenomena was exhibited by changes in the helical coil bond strength.

\begin{tabular}{|c|c|c|c|c|c|c|}
\hline Resulls a & $\begin{array}{l}\text { Varnish } \\
\text { tet } 500-11\end{array}$ & $\begin{array}{r}\text { h Coated } \\
\text { BOND } \\
1011 \text { Expos }\end{array}$ & $\begin{array}{l}\text { on Magne } \\
\text { STRENGT } \\
\text { sure plus }\end{array}$ & $\begin{array}{l}\text { et Wire A } \\
\text { H } \\
+24-h o u l\end{array}$ & all bake: :6 & 1500 \\
\hline & & & Valmoli 1 & ype & & \\
\hline & 1475 & $139 i$ & 28.616 & 1.532 & 12. 223 & $5 x$ \\
\hline benexposed & 73.1 & 436 & $5: 5$ & 9911 & 4.71 & +52 \\
\hline $1 \ldots$ & & $20 \mathrm{Ch}$ & ancle flom & Unexpose & & \\
\hline Deroure if & $1+475$ & 290 & 5.610 & $1-833$ & 48.223 & $2=2 x$ \\
\hline 126000 & $.58 \pi$ & $238 \%$ & $69 t$ & $56.2 \%$ & $124 \%$ & $235 \%$ \\
\hline 1) 900 & $159 *$ & $260 \%$ & $3 ? 54$ & 3534 & $=94 t$ & \\
\hline $1+6+22$ & $946 \%$ & $\because 96$ & 90.84 & $1.4,04$. & 8390 & $\div$ F. \\
\hline$+1 \div=8: 23$ & $.10 \%$ & $128 \%$ & $50 y r_{i}$ & $49: 4$ & $660_{i}$ & $\therefore=140$ \\
\hline $14-60-124$ & $03 \%$ & $227 \%$ & $3-74$ & $1340_{n}$ & b. $2 \pi$ & $E 5 \%$ \\
\hline 14c 1.421 & $-9 \times 2 \%$ & $305 \%$ & $223 \%$ & $36 ; 10$, & $2^{2} \quad 5 * 0$ & $\because 440$ \\
\hline HFC Iscá & 91240 & $8314=$ & $8+40^{\circ}$ & $15 x^{3}+4$ & $14+4$ & if $7 \pi$ \\
\hline 145.1349 & $190 \%$ & $111 \%$ & Fin & 404 & $\rightarrow \tau, u_{\tau}$ & $57 \%$ \\
\hline HFE 13.4 & $311 \%$ & $455 \%$ & $233 \%$ & 20140 & $213 \pi$ & $\therefore 2 \%$ \\
\hline 1150.125 & $107 \%$ & $420 \%$ & $135 \%$ & $291 \%$ & $\because 153 \times 1$ & $21+4$ \\
\hline $\begin{array}{l}\text { HFE } 3{ }^{2} \\
\text { HFE. } 1.43 A\end{array}$ & $\begin{array}{r}662 \% \\
4 \% 96\end{array}$ & $\begin{array}{ll}30 & 150 \\
22 & 30\end{array}$ & $\begin{array}{llll}9 & 2 & 4 & 0 \\
1 & 2 & 5 & -4\end{array}$ & $\begin{array}{l}26.94_{i} \\
13.4 c_{r_{i}}\end{array}$ & $\begin{array}{l}56 \\
20\end{array}$ & 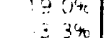 \\
\hline $\begin{array}{l}H F=.133 \\
H F=245 c a\end{array}$ & .40840 & 13.140 & $\because 80_{0}$ & 17.4 & 300. & $1=12$ \\
\hline
\end{tabular}

Talile? 
Refrigerant HCFC-22 had the greatest effects $-20 \%$ to $-49 \%$ ) on the bond strenguts of magnet wire A (polyester with amide imide overcoat) with the six varmishes as measured immediately after the exposure. After bakeout of HCFC. -22 the bond strength was reduced -38 to $-95 \%$. Exposure to HFC-32 (-19 to $-86 \%)$ and HFC-152a $(-19$ to $-91 \%)$ also produced greatly decreased bond strengths atter bakeout. Significant decreases in bond strengths were also observed for magnet wire $B$ (glass served) with the six varnishes after exposures to HFC. $22(-20$ to $-59 \%)$, HFC. 32 ( -6 to $-75 \%)$. HFC -152 a $(-7$ to $-59 \%)$ and HCFC- $123(+1$ to $-80 \%$ ). For magnet wire $\mathrm{C}$ (esterimide:amide-imide) similar losses of bond strength were measured for HCFC-22 (-45 to $-84 \%)$ and HFC- $32(+13$ to $-95 \%)$ but not for HFC-152a. HCFC-123 or other refrigerants.

In general, the helical coll bond strength of the varmished magnet wires was decreased by the effects of absorption and desorption of refrigerants. The refrigerant having the greatest effect was HCFC-22. Bond strength for the 833 varnish was less than the other varniches, but should not be compared to the other varmishes because the 833 is used primarily for its electrical insulation properties rather than its bond strength.

\section{Burnout Strength}

Burriout strength was also measured on the vamished and unvarnshed magnet wires before and after exposures to refrugerants and reficjerants-lubricants The burnout test smmates the effects of hugh current loads on motor stators that may occur during start up or other transient conditions. The burnout test apples a 120 volt $A C$ cument over tume through iwisted pairs, causing resistance heating of the wire and recolds the time at which the insulation fals

The amount of refrigerant absorbed and the effect of the $150 \mathrm{C}\left(302^{\prime \prime} \mathrm{F}\right.$ ) bake had less effect on bumout strength than on the other properties of the magnet wire. This results because the burnout test heated the wire similar to the bake out, except to higher temperatures and faster. In many mstances, the effect on the burnout strengths of the wires was greater when the absorbed refrigerant was not completely expelled prior to the test.

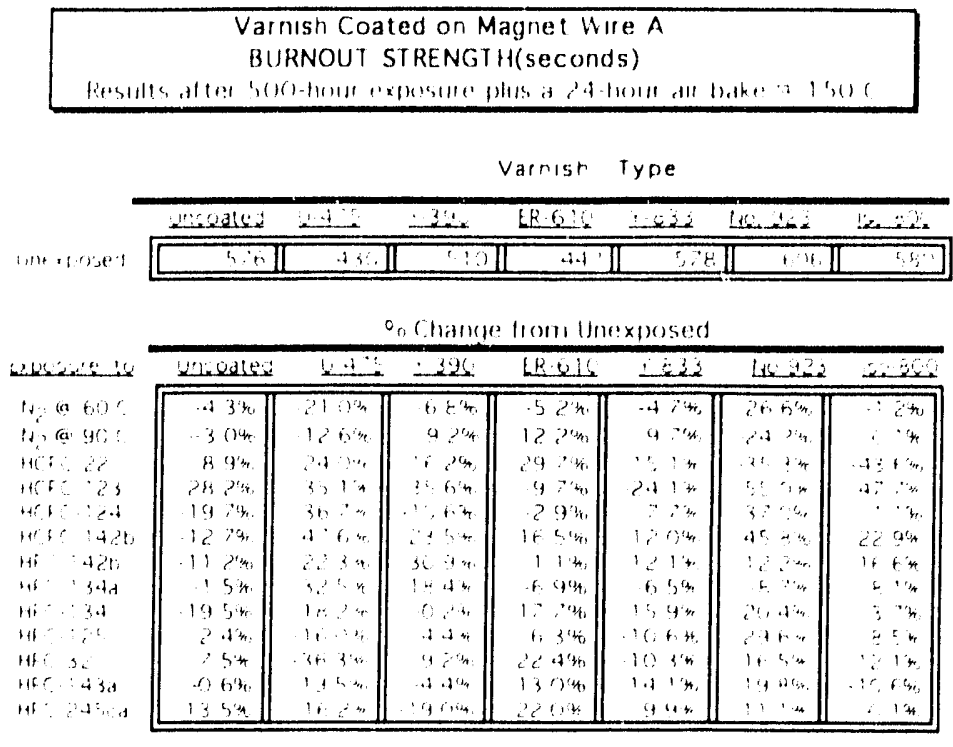

I athe? 3

The most important information revesled from the burnout test is the superior performance of magnet wire B (glass served) compared with the other types of magnet wires. The unexposed magnet wire $B$ shows a burnout time of 736 to 755 seconds compared to 430 to 600 seconds for magnet wire $A$ (ester with amide-imide overcoat) and 469 to 632 seconds for magnet wire C(ester-imide with amide-imide overcoat). These times translate into significant differences in temperature resistance of the three types of wire insulation. Secondly, exposures to refrigerants had very lit tle effect on the burnout time of magnet wire $B$ compared to the other wire types.

\section{Dielectric Strength}

The test for dielectric strength of magnet wire used the same type of twisted pairs that were used for the burnout test. Rather than increasing the current with time, the voltage between the two wires was increased until there was dielectric breakdown of the insulation and a spark jumped between the two wires. This dielectric breakdown voltage was automatically recorded.

For magnet wire $\mathrm{A}$ (ester with amide-imide overcoat), the greatest decrease in dielectric breakdown voltage results after desorption of refrigerant. As observed previously from the degradation of varnish disks, the greatest effects resulted from exposures to HCFC $-22(+8.8$ to 
$-69.9 \%)$, HFC-32 (-2.2 to $-59.0 \%)$ and R152 a $(-1.0$ to $-50.1 \%)$. Results for magnet wire $\mathrm{C}$ (ester-imide with amide-imide overcoat) were very similar to those for magnet wire $A$. The dielectric strength of magnet wire $B$ (polyester-glass served) was less affected by refrigerant exposure than the other magnet wire types. Surprisingly the dielectric strength of unexposed magnet wire $B$ was less than the dielectric strength of other magnet wires.

\section{Varnish Coated on Magnet Wire A DIELECTRIC STRENGTH}

Results atter 500-hour exposure plus a 24 -houl all bake @ $150 \mathrm{C}$

\begin{tabular}{|c|c|c|c|c|c|c|c|}
\hline \multirow{3}{*}{ Unexposed } & Unceated & $0-475$ & 1.390 & ER-6]0 & $\lcm{1.833}$ & No. 923 & LS1-800 \\
\hline & $15.8 \mathrm{kV}$ & $162 \mathrm{kV}$ & $188 \mathrm{kV}$ & 156.4 & $120 \mathrm{kV}$ & $168 \mathrm{VV}$ & 19111 \\
\hline & \multicolumn{7}{|c|}{$\%$ Chancle from lnexposed } \\
\hline Exposure 10 & Uncoaseo & $1-475$ & $1 \cdot 390$ & EF. 610 & 1.833 & No. 223 & $120-800$ \\
\hline$N_{2}$ @60 & $9.4 \%$ & $.11 .0 \%$ & $.12 .4 \%$ & $194 \%$ & $.93 \%$ & $.302 \%$ & $-118 \%$ \\
\hline $1 \sqrt{2} @ 90 \mathrm{C}$ & $.142 \%$ & $85 \%$ & $11.2 \%$ & $102 \%$ & $57 \%$ & $.154 \%$ & $\because 64$ \\
\hline HCFC. $2 i$ & $88 \%$ & $\begin{array}{r}184 \% \\
.30 \%\end{array}$ & $-44.8 \%$ & $4 \div 210$ & $-2.9 \%$ & $-161 \%$ & -69.94 \\
\hline & $\begin{array}{r}150 \% \\
28 \%\end{array}$ & $\begin{array}{l}.30 \% \\
.5 .5 \%\end{array}$ & $\begin{array}{r}-199 \% \\
.7 .6 \%\end{array}$ & $\begin{array}{l}\because 14 \% \\
\therefore 35 \%\end{array}$ & $\begin{array}{r}919 \% \\
.122 \%\end{array}$ & $\begin{array}{l}30 \% \\
193 \%\end{array}$ & $\begin{array}{l}269 \% \\
138 \%\end{array}$ \\
\hline HCFC. $1+2 \mathrm{H}$ & $.9 .8 \%$ & $0.0 \%$ & $.80 \%$ & $92 \%$ & $.117 \%$ & $.9 .5 \%$ & $29 \%$ \\
\hline $\mathrm{HFC} \cdot 142 \mathrm{E}$ & $-1.0 \%$ & $.84 \%$ & $-40.5 \%$ & $.251 \%$ & $.64 \%$ & $-50.1 \%$ & .2464 \\
\hline$H F C-134 a$ & $204 \%$ & $.18 .1 \%$ & $.171 \%$ & $142 \%$ & $.183 \%$ & $84 \%$ & $205 \%$ \\
\hline HFC -134 & $227 \%$ & $-259 \%$ & $382 \%$ & $219 \%$ & $.18 .8 \%$ & $308 \%$ & $79 \%$ \\
\hline PFC. 125 & $132 \%$ & $\because 3 \%$ & $-214 \%$ & $153 \%$ & $34 \%$ & $7.5 \%$ & $.21 \%$ \\
\hline HFC. $3 ?$ & 2240 & $-21.0 \%$ & $.54 .0 \%$ & $5+\% 6$ & $70 \%$ & $-59.0 \%$ & $.28 .9 \%$ \\
\hline$H F C \cdot 143 a$ & $-01 \%$ & $23.2 \%$ & $66 \%$ & $47 \%$ & $.01 \%$ & $19.3 \%$ & $-192 \%$ \\
\hline HFC $-245 \mathrm{Ca}$ & $18.2 \%$ & $16.2 \%$ & $-190 \%$ & 22614 & .994 & 1119 & i) 19 \\
\hline
\end{tabular}

Table 4.

\section{SUMMARY}

Absorption of HCFC-123 by most motor materials was higher than for other refrigerants. However, absorption of HCFC-22. HFC-32, HFC-134 and HFC-152a followed by desorption at higher temperatures, resulted in greater damage to the insulation material than was observed with HCFC-123. This result suggests that high internal pressures and rate of refrigerant desorption is as important as the amount of refrigerant absorbed. Desorption of refrigerant caused blisters. cracks, internal bubbles and delamination. The measured effects on properties of some materials was a decrease of bond strength(as high as 95\%), a decrease of dielectric strength(as high as $70 \%$ ), and a decrease of the physical integrity of the material. Compared to the bond and dielectric strengths, burnout was less influenced by desorption prior to the test. The burnout test caused desorption of refrigerant during the test. Magnet wire with polyester-glass serving had the best burnout resistance and was influenced much less by the exposure to absorbed refrigerant.

Of the 11 refrigerants tested, HCFC-22 produced the greatest effects on motor materials. Since HCFC-22 has an excellent reliability history with many of these materials, the alternative refrigerants are also expected to be compatible with most materials.

\section{REFERENCES}

[1] R.G. Doerr, D. Lambert, R. Schafer, and D. Steinke, "Stability and Compatibility Studies of R245ca, $\mathrm{CHF}_{2}-\mathrm{CF}_{2}-\mathrm{CH}_{2} \mathrm{~F}$, a Potential Low-Pressure Refrigerant", International CFC and Halon Alternatives Conference, Washington, DC, September 30, 1992, Proceedings pp. 147-152.

[2] American Society for Testing and Mat erials (ASTM) D-149-91, D-1676-92, and D-2519-91, Vol. 10.01 and 10.02, 1992.

[3]. R.G. Doerr and S.A. Kujak, "Compatibility of Refrigerants and Lubricants with Motor Materials, Final Report", May 1993. ARTI Refrigerant Database.

[4] R.G. Doerr, "Absorption of HCFC-123 and CFC11 by Epoxy Motor Varnishes". ASHRAE Annual Meeting, Baltimore, MD, June 30, 1992. Transactions Vol. 98(2), pp. 227-234. Varnish $C$ is Y-833.

\section{ACKNOWLEDGMENT}

Richard Ernst for the direction and scope of this project.

Technicians: Aaron Clark. Fred Howard, John Miller, and Todd Waite for preparation and evaluation of samples.

Many companies for refrigerants, lubricants, and motor mat erials.

The Department of Energy(DOE) for major funding (Grant DE-FG02-91CE23810), and Mark Menzer and Steve Szymurski of the Air-conditioning and Refrigeration Technology Institute(ARTI) for administration of the project.

EEIC/ICWA Exposition, October 6,1993; Rosemont, IL; Proceedings, pp. 513-517. 

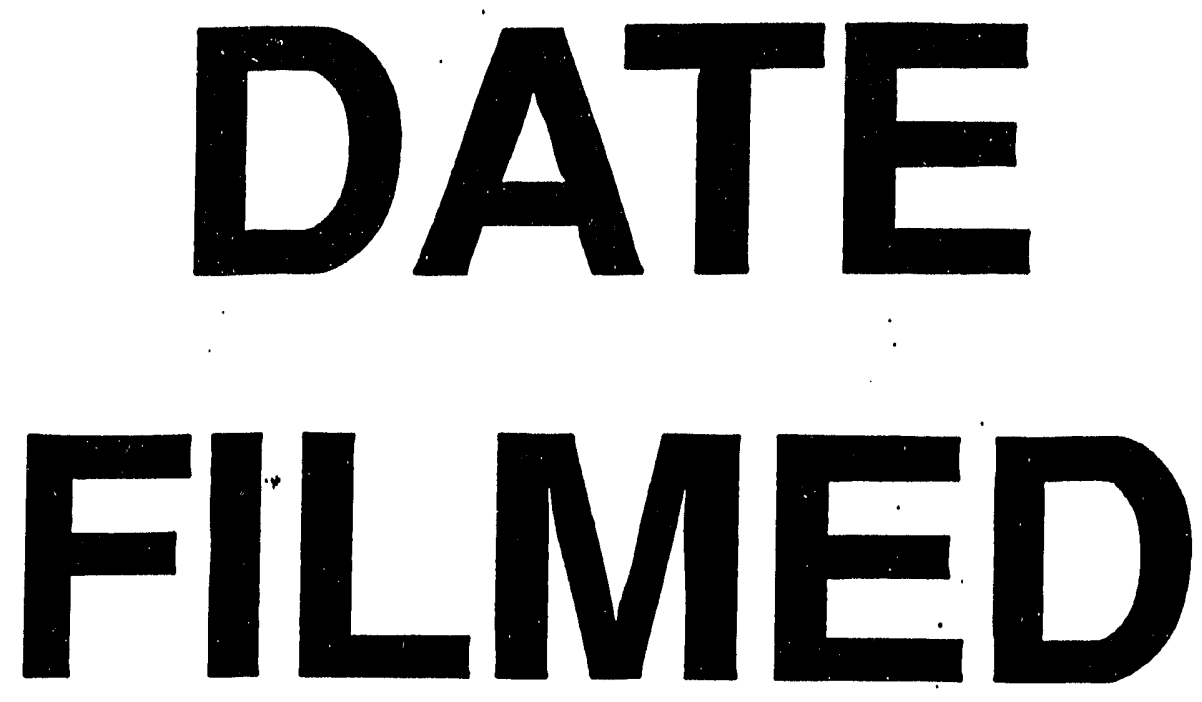

$12 / 29 / 93$
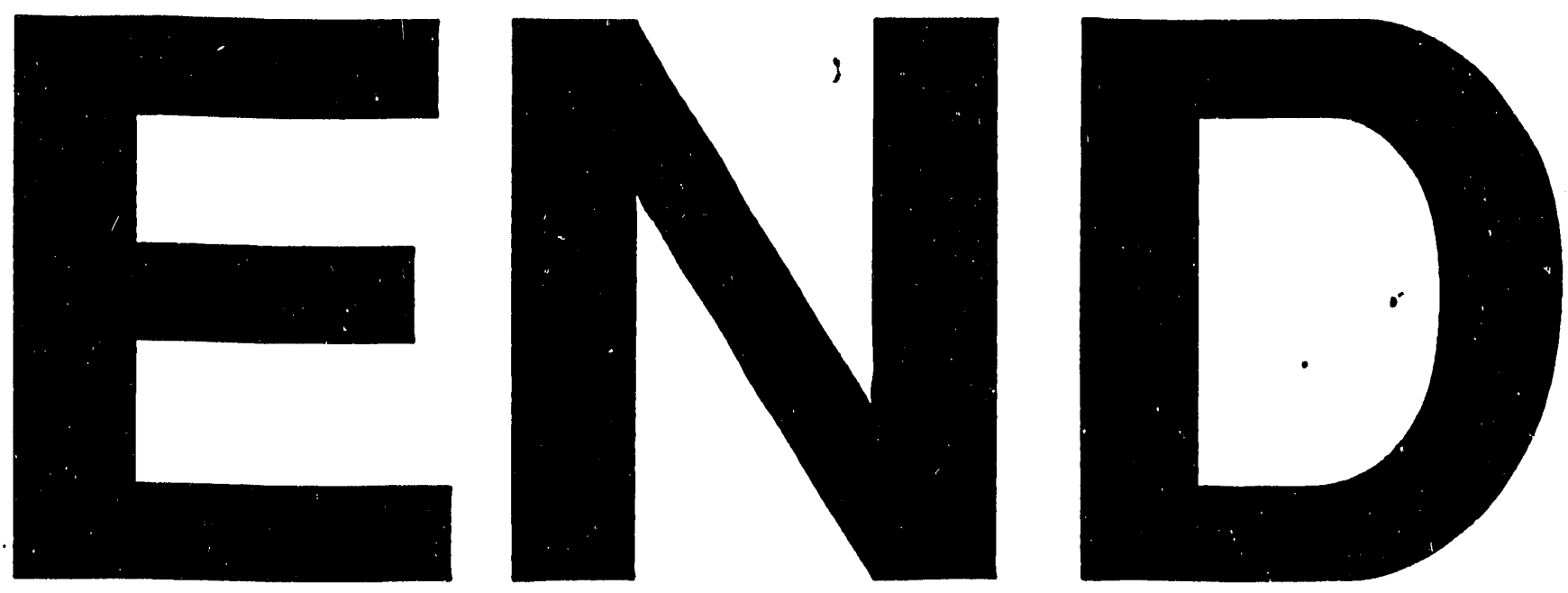
